\title{
Analysis of Shielding Effectiveness on Al6061 Composite Material Reinforced with Fly Ash for Oblique Incidence
}

\author{
Srinu Budumuru, M. Satya Anuradha, B Siva chakra Avinash, C Dharma Raj
}

\begin{abstract}
Over last two decades a high extent of concentration is on reducing the weight of the commercial aircraft with enough mechanical properties like strength, stress etc. Composite materials are preferable for construction aircrafts with less weight and good mechanical properties. But these composite materials have very less conductivity, suppose if the lightning strikes the aircraft flow of current through exit terminals of it was not possible, so there is a possibility for physical damage of the aircraft. To overcome the lightning effect on aircraft lightning strike protection (LSP) should be involved, for that in the present work AL6061 composite was considered for the construction of aircraft. To improve the shielding and mechanical properties of the material, fly ash particles are reinforced at different percentages. Electromagnetic shielding and mechanical properties are measured for the above material at $X$ band. $M A T L A B$ Simulation results are compared with the conventional AL6061 composites for arbitrary case.
\end{abstract}

Keywords: AL6061, Aircraft lightning strike protection, $X$-band frequency, mechanical properties of material.

\section{INTRODUCTION}

Most of the cases EM waves from lightning strikes the surface of aircraft arbitrary instead of normal. Aluminum composites are the prime material for the fabrication of aircraft in term of less weight, good strength and SE. In the present work electromagnetic shielding effectiveness and mechanical properties of the AL6061 composite were measured by reinforcement of fly ash at different quantities. This composite material can be used for the construction of the aircraft to satisfy above constraints with LSP [1]. Flyash has the properties that it absorbs electromagnetic waves propagates through it, reinforcement of flyash particles improves the shielding properties [2]. Stir casting process introduced for the reinforcement of flyash particles at 5\%, $10 \%, 15 \%$ at an temperature of $600^{\circ}-700^{\circ} \mathrm{C}$. Liquid AL6061 composite poured in wood boxes to built strips at required size. The electrical parameters those composite strips can be measured based on vector network analyzer (VNA) [3].

Revised Manuscript Received on December 13, 2019.

Srinu Budumuru ${ }^{1}$, department of ECE, GITAM Deemed to be university, Visakhapatnam, India. Email: srinu.budumuru@gitam.edu

M. Satya Anuradha ${ }^{2}$, department of ECE Andhra University, India Email: radhamsa@gmail.com

B.siva chakra avinash, department of ECE , GITAM Deemed to be university, Visakhapatnam, India. Email:bscavinash1997@gmail.com

C Dharma Raj ${ }^{1}$ department of ECE, GITAM Deemed to be university, Visakhapatnam, India. Email:dharmaraj.cheruku@gitam.edu
* Correspondence Author

\section{SHIELDING EFFECTIVENESS OF AL6061 COMPOSITE FOR OBLIQUE INCIDENCE:}

Impedance of the metal sheet given as

$$
\begin{gathered}
\eta=\sqrt{\frac{j \omega \mu}{\sigma}}=(1+j) \sqrt{\frac{\pi \mu f}{\sigma}} \\
Z_{j}=\frac{n_{j}}{\cos _{j}} \text { Transverse Electric Polarization } \\
n_{j} \cdot \cos \theta_{j} \text { Transverse Magnetic Polarization }
\end{gathered}
$$

$\cos \theta_{j}$ can be defined using Snell's law as

$$
\cos \Theta_{j}=\sqrt{\left[1-\left(\frac{k_{1}}{k_{j}}\right)^{2} \cdot \sin ^{2} \Theta_{1}\right]}
$$

$\theta_{j}$ is angle of refraction of ' $\mathrm{j}$ ' th medium

Wave number given as

$$
k_{j}=\omega \sqrt{\left[\mu_{j}\left(\varepsilon_{j}+\left(\sigma_{j} / j \omega\right)\right)\right]}
$$

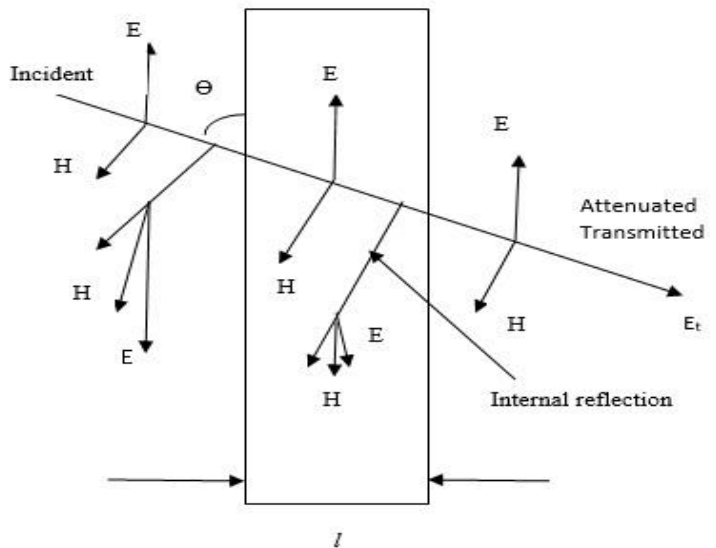

Figure1: Representation of shielding effectiveness of plane sheet with respective oblique incidence.

$$
Z=\eta \cdot \frac{z(l) \cosh y l+\eta \sinh y l}{\eta \cosh y l+Z(l) \sinh y l}
$$

Impedance right to plane $x=l$ taken as $Z(l)$ 
Analysis of Shielding Effectiveness on Al6061 Composite Material Reinforced With Fly Ash for Oblique Incidence

$p_{H}=\frac{4 z_{\omega} \eta}{\left(z_{\omega}+\eta\right)(z(l)+\eta)} q_{H}=\frac{\left(z_{\omega}-\eta\right)(z(i)-\eta)}{\left(z_{\omega}+\eta\right)(z(i)+\eta)}$

when $Z(l)=Z_{w}$

$$
T=p\left(1-q e^{-2 y l}\right)^{-1} e^{-\gamma l}
$$

Shielding can be defined as

$$
S=-20 \log _{10}|T|
$$

Shielding effectiveness of shield can be measured as a sum of absorption loss and reflection losses [4][5][6].

Electrical parameters of Al6061 Composite: Based on transmitted and reflected EM waves using wave guide method electrical parameters of composites were found and given as follow.

\section{RESULTS:}

Table 1: Al6061 reinforced with 5\% of Flyash:

\begin{tabular}{|c|c|c|c|}
\hline $\begin{array}{c}\text { Frequency } \\
(\mathbf{G H z})\end{array}$ & $\boldsymbol{\mu}_{\boldsymbol{r}}$ & $\boldsymbol{\sigma}_{\boldsymbol{r}}$ & $\boldsymbol{\epsilon}_{\boldsymbol{r}}$ \\
\hline 8.2 & -8.6 & 0.232 & 4.94 \\
\hline 9 & 0.375 & -0.312 & 1.49 \\
\hline 10 & -0.519 & 0.796 & 5.65 \\
\hline 11 & 0.31 & -3.85 & 9.75 \\
\hline 12 & 0.0366 & -0.787 & 9.75 \\
\hline
\end{tabular}

. Table 2: Al6061 reinforced with $10 \%$ of Flyash:

\begin{tabular}{|c|c|c|c|}
\hline Frequency $(\mathbf{G H z})$ & $\boldsymbol{\mu}_{\boldsymbol{r}}$ & $\boldsymbol{\sigma}_{\boldsymbol{r}}$ & $\boldsymbol{\epsilon}_{\boldsymbol{r}}$ \\
\hline 8.20 & -5.91 & 0.26 & 2.69 \\
\hline 9.00 & 0.22 & -2.95 & 15.60 \\
\hline 10.00 & 0.81 & -1.57 & -13.20 \\
\hline 11.00 & 0.25 & -8.72 & 15.10 \\
\hline 12.00 & -0.04 & -5.10 & 19.60 \\
\hline
\end{tabular}

Table 3: Al6061 reinforced with 15\% of Flyash:

\begin{tabular}{|c|c|c|c|}
\hline Frequency $(\mathbf{G H z})$ & $\boldsymbol{\mu}_{\boldsymbol{r}}$ & $\boldsymbol{\sigma}_{\boldsymbol{r}}$ & $\boldsymbol{\epsilon}_{\boldsymbol{r}}$ \\
\hline 8.2 & -4.71 & 0.22 & 1.82 \\
\hline 9 & 0.19 & -1.96 & 12.50 \\
\hline 10 & -0.36 & 0.33 & 3.18 \\
\hline 11 & 0.27 & -1.55 & 8.83 \\
\hline 12 & 0.07 & 0.07 & 12.00 \\
\hline
\end{tabular}

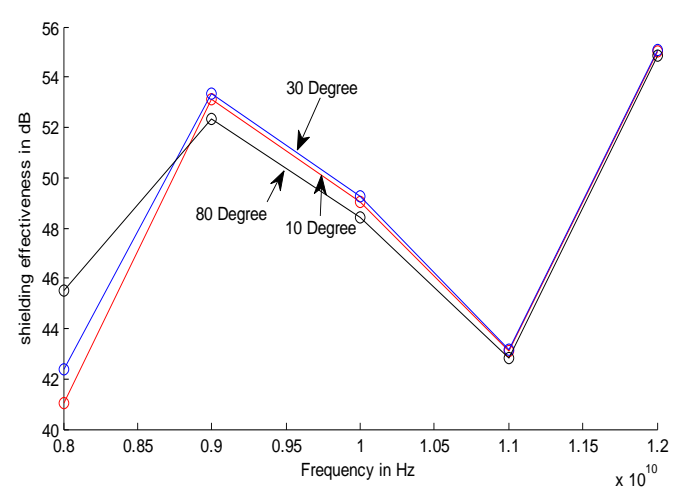

Figure 2: SE of AL6061 reinforced with $5 \%$ of flyash at different angle of incidence with frequency.

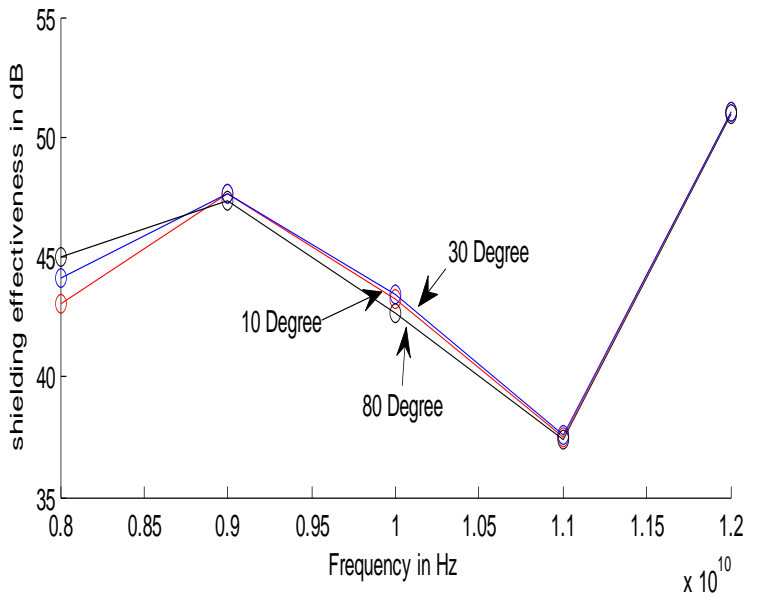

Figure 3: SE of AL6061 reinforced with $10 \%$ of flyash at different angle of incidence with frequency.

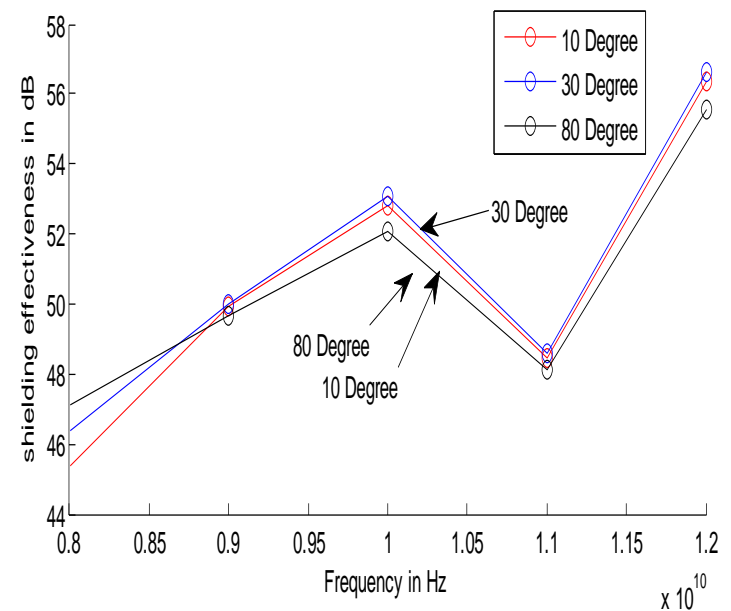

Figure 4: SE of AL6061 reinforced with 15\% of flyash at different angle of incidence with frequency.

From Figure 2 to Figure 4 shows that Shielding effectiveness of AL6061composite improving with increasing the add mixture flyash particles. SE analyzed for $10^{\circ}, 30^{\circ}, 80^{\circ}$ of angle of incidence.

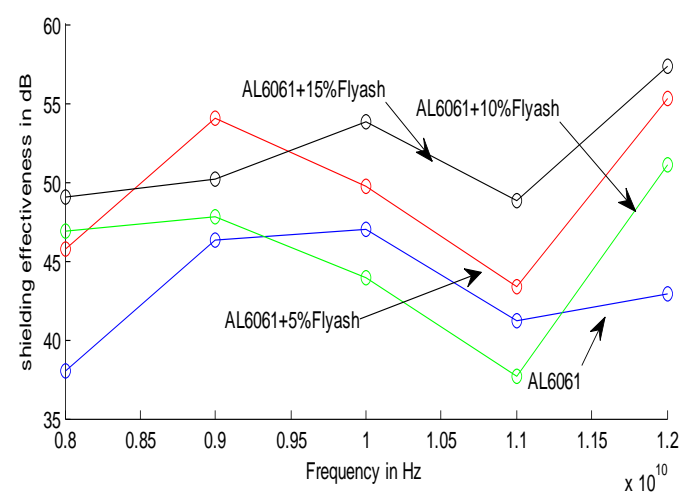

Figure 5: Comparison plot for SE and frequency for Different add mixture of flash at $30^{\circ}$ angle of incidence. 


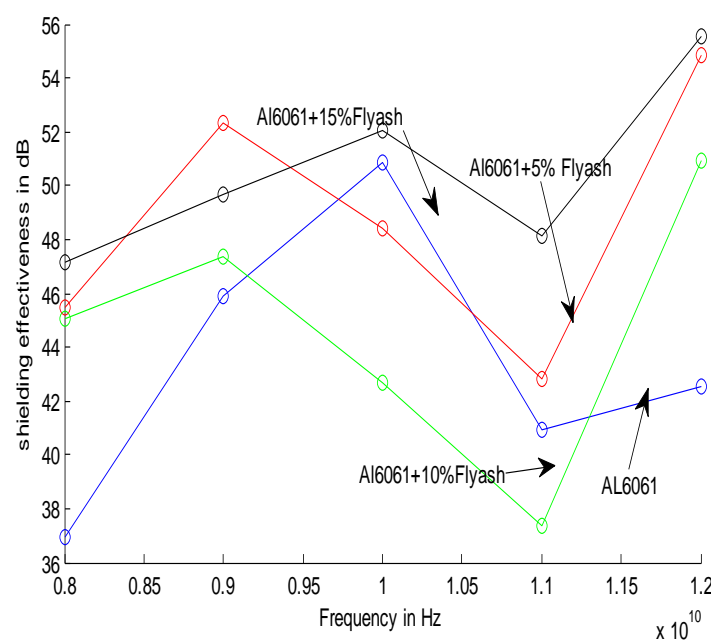

Figure 6: Comparison plot for $\mathrm{SE}$ and frequency for Different add mixture of flash at $80^{\circ}$ angle of incidence. Figure 5 and figure 6 shows shielding effectiveness of aluminum composite at different angle of incidence $\left(30^{\circ}\right.$ and $80^{\circ}$ ). Here as the angle of incidence increases shielding effectiveness decreases.

Mechanical properties of composite:

Experimentation conducted on composite at different levels of reinforcement of flayash. Brinell hardness test, Universal tests was used for finding hardness and tensile strength.

Table 5: Comparison of SE at different angle of incidence.

\begin{tabular}{|c|c|c|}
\hline Material & $\begin{array}{c}\text { SE in dB } \\
(\text { Incidence at 30 }\end{array}$ & $\begin{array}{c}\text { SE in dB } \\
(\text { Incidence at 80 }\end{array}$ \\
\hline AL6061
\end{tabular}

Table 6: Experimental results of tensile strength and hardness

\begin{tabular}{|c|c|c|c|c|}
\hline MATERIAL & $\begin{array}{l}\text { AL606 } \\
1\end{array}$ & $\begin{array}{l}\begin{array}{l}\text { AL6061 } \\
+ \\
\% 5\end{array} \\
\text { Flayash } \\
\end{array}$ & $\begin{array}{l}\begin{array}{c}\text { AL6061 } \\
+ \\
\% 5 \\
\text { layash }\end{array} \\
\end{array}$ & $\begin{array}{c}\text { AL6061 } \\
+ \\
\% 5 \text { Flayash }\end{array}$ \\
\hline $\begin{array}{c}\text { Tensile } \\
\text { strength }\end{array}$ & 110 & 124 & 126 & 128 \\
\hline Hardness & 33 & 47 & 55 & 60 \\
\hline
\end{tabular}

\section{Conclusion:}

In the aerospace industry to provide lightning strike protection materials with good shielding properties, less weight and strong mechanical properties are required. In the present work AL6061 composite material was proposed with different levels of add mixture of flayash particles, shielding properties for oblique incidence at $10^{\circ}, 30^{\circ}, 80^{\circ}$ was measured and observed that SE improving with percentage of flash.Tensile strength and hardness also improving with admixture level of flyash. There is an increment of $15 \mathrm{~dB}$ in the shielding effectiveness for $15 \%$ of einforcement of flyash, So this material can be used for aerospace application to provide lightning strike protection(LSP).

\section{REFERENCES}

1. Larsson A. 2002 The interaction between a lightning flash and an aircraft in flight. ComptesRendus Physique.;3:1423-1444

2. Yinsuo Dai, Jianhua Wu, DerongWang, Effect of Mineralogical Phase and Chemical Composition of Fly Ashon Electromagnetic Wave-Absorbing Properties, Materials Transactions, Vol. 59, No. 6 (2018) pp. 876 to 882 .

3. U. C. Hasar ."Permittivity Measurement Of Thin Dielec- Tric Materials From Eflection-Only Mea- Surements Using One-Port Vector Network Analyzers", PIER 95, 365\{380, 2009\}.

4. Richard.B.Schulz, V. C. Plantz, D. R. Brush, ShieldingTheory and Practice, IEEE Transactions on ElectromagneticCompatibility, Vol 30, No. 3, Aug. 1988, pp 187-201.

5. C D Raj, G S Rao, P V Y Jayasree, B Srinu, P Lakshman, Analysis of Reflectivity and Shielding Effectiveness of Absorbing Material-Conductor Laminate forElectromagnetic Compatibility, JEMAA, 2010.

6. C D Raj, G S Rao, P V Y Jayasree, B Srinu, P Lakshman, Estimation of reflectivity and shielding effectiveness of three layered laminate electromagnetic shield at X-band, PIER B, Vol. 20, 205\{223, 2010\}.

\section{AUTHORS PROFILE}

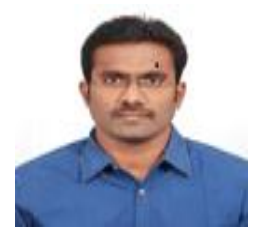

Srinu Budumuru Working as Assistant professor at GITAM University . Area of research is Antennas, EMI/EMC.

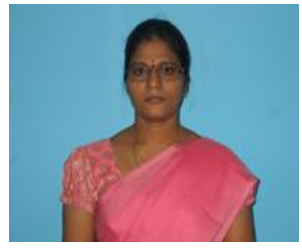

M. Satya Anuradha Working as Professor at Andhra University. Area of research is Antennas, EMI/EMC.

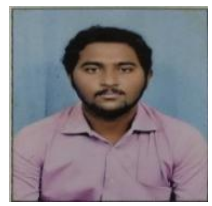

B Siva chakra Avinash Research scholar at GITAM Deemed to be University. Area of research is Antennas, EMI/EMC.

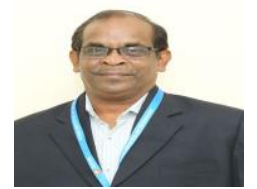

C Dharma Raj Working as Professor at GITAM Deemed to be University. Area of research is Antennas, EMI/EMC. 